\title{
PSYCHOLOGYCAL STABILITY, AGGRESSIVENESS AND PERSONAL CHARACTERISTICS OF ELITE BULGARIAN BOXERS
}

\author{
Ivan Ivanov \\ National Sports Academy „Vassil Levski“, Sofia, Bulgaria
}

\begin{abstract}
In the game of boxing, psychological stability is based on a different personality characteristics_like emotional and behavior control. In this study we attempt to establish the boxers' traits and to find out relationships between them, and to compare the results by gender and age. Another important parameter is the aggressiveness and how boxers deal and control it before and during match.

Methodology: 1)Big Five Personality Test developed by Goldberg (1992) 2) The Aggression Questionnaire (Buss, A.H., \& Perry, M., 1992) 3) Test for Personality Hardiness. Building a tool for measuring personality hardiness began in 1982 and in 1989 resulted (Bartone, Ursano, Wright, Ingraham) a questionnaire with 45 items.

Results: The results of our research reveal that the scale with the highest result is Agreeableness, which is the trait described with high level of politeness, trustiness and strong behavior control. We have significant differences by gender parameters

Conclusions: The results show that the Agreeableness is the parameter with the highest score and is leading in elite boxers in Bulgaria. The female boxers have the higher level of Openness and Challenge. Verbal aggression is higher than physical. There is a lot of aggression in boxing but with clear rules and parameters. The good boxer need to control his (her) behavior.
\end{abstract}

Key words: psychological stability, aggressiveness, personal characteristics, boxers

\section{INTRODUCTION}

Boxing is a kind of sport in where the competitors need a lot of different technical and physical skills, but the crucial abilities are psychological. They include-emotional self-control, confidence, high level of attention focus during the match and fast and quick decision making. The boxers need to improve their impulse control and in the same time they need to act spontaneously. On a first sight box is very aggressive sport, but the best of the competitors can hold their anger in a normal level. There is a lot of situations in this sport which can be considered and experienced like challenge and danger. One of the most important factors in sport is the psychological stability and hardiness. The term Hardiness has been studied in three components- Commitment, Control and Challenge in most of the scales (Kobasa, 1979; Kobasa, 1982; Maddi and Kobasa, 1981; Maddi, 2006; Bartone, 2006; Sinclair, R.R.,\& Tetrick, L.E., 2000).) and in terms of four components, i.e., confidence (as well as commitment, control and challenge) as perceived by Hull et al. (1987) and the scales range from ,strongly agree" to "strongly disagree" except the hardy surveys which measure stress, strain, hardy attitude etc. The scales are very useful for attitude measurement, provide strong and valid assessment, and it is easy for item analysis evaluations and quick and economical to administer and score.

Hardiness is a collection of personality traits that function as resource across with stressful life events. The scale has tree subscales: Commitment- a tendency to involve someone in whatever he or she is doing. It involves commitment towards learner, work, profession, society, human values, family, friends, religious faith. Control- a tendency to feel and act as if one is influential and control his or her life. It implies the perception of oneself as having a definite influence through the experience, knowledge, skills and choices. Challenge - a belief that change is better than stability and it is normal in life and these are important, interesting incentives to growth rather than threats to security. The scale was prepared on the above mentioned three components of personality hardiness. The proposed components of the hardiness construct were not the result of empirical studies, but of a theoretical model of the person as active actor who chooses his/her strategies and goals (Maddi \& Kobasa, 1981). 
According to (Williams \& Krane, 2001) hardiness, may account for up to $90 \%$ of success in sport. We can suppose that, relative to other competitive standards, competitors operating at the highest level in sport would score significantly higher in hardiness. The more their sport experience is, the higher their hardiness will be (Golby and Sheard, 2004). Also, female athletes show higher hardiness than female non-athletes and this results from the positive effect of sport on hardiness (Mohammadifar et al, 2010). The aggression in most of the sports is very common component with different meaning and interretations. In psychology terms aggressiveness can be defined as a human characteristic manifesting itself in inclinations to hurt others, to destructive behavior. Aggression is a personality trait that has been associated with sport participation. It is operationally defined as an intentional physically or psychologically harmful behavior that is directed at another living organism (Thirer, 1993). The frequency of aggression in sports on all levels has survived in a lot of academic research.

The International Society of Sport Psychology recently recognized that sport aggression is a_part of sport game and has recommended ways to curtail this behavior. With reference to sport, Husman \& Silva (1984) show and define aggressiveness as bold and energetic pursuit of a goal. These Authors distinguish three types of aggression (aggressiveness) in sport: 1) proactive assertiveness, 2) instrumental aggression, 3) reactive aggression.

Many coaches and sports scientists believe that aggression in sport is a positive behavior, an expected way to achieve success. From the perspective of sport psychology, it may be said that the aggressiveness specificity depends on the group of individuals it concerns. Aggression manifestation in sport may be more humane than typical aggression as it is commonly understood. The aggression manifestation must not always take the form of inflicting pain or suffering, or of demeaning other people.

Aggression in sport is also a way to intimidate the opponent. The concept is defined as a tool to control the behavior of the opponent by causing fear (Crawford et al., 2004). It can be done intentionally, when the aggression is intended not only to cause physical injury but also to intimidate the opponent. This situation occurs when an opponent's aggressive action is perceived as intimidating even when this was not the intention of the offender.
If we look at the effect of aggressiveness on athletic performance, various empirical studies show different results in different sports. However, Widmeyer and Birch (1984) found no such relationship with team performance. Meanwhile, Andrews (1974) found a positive relationship between the number of victories of ice hockey teams and the penalties awarded against them.

It is clear that in every sport the goals have direct relationship with personality profile of athletes. Iancheva (2004) describe the various and differences in elite sport based on the extraordinary expectations toward the personality of athletes, their development and sport performance. A lot of these circumstances make the role of personal integrity and grow up an essential factor for the preparation and realization of competitive strategies. The personality is the center of the sport performance and career development.

Athletes are remarkably varied in their ability to perform under stressful or challenging circumstances. To understand and encourage behavior change, the sources of these personality traits need to be uncovered. One of the famous and most used personality tests is Big Five. Investigations have explored associations between personality traits and performance-related outcomes (e.g., academic and occupational success) Amid the academic articles available, a considerable number have centered on personality-trait associations in the context of sport and physical activity. Goldberg's model is known as the "Big five" and it has five traits - Extraversion, Agreeableness, Conscientiousness, Emotional stability and Intellect (Goldberg, 1990, 1992)

Structure of athletes' personality was often subject of sport psychologists' researches. Understanding personality structure, basically, is to determine prominent individuals' disposition: specific, which control behavior of one type situation, and general, which are in the base of behavior in a lot of situations. Athletes' personality is significantly different compared with non-athletes.

The aim of the research is to explore the relationship between personality characteristics and aggressiveness in elite Bulgarian boxers.

To achieve that aim we set following tasks:

1 . To find out and measure personality characteristics of boxers;

2. To find out and measure the levels of psychological stability and aggressiveness. 
3. To find out how the factors such as gender, age, professional experience and qualification level influenced the research factors.

4. To find how personality traits influence the levels of aggression.

\section{METHODS}

The following research was realized during tree training camps in the winter and spring 2019 year with male and female boxers from different national teams of Bulgaria. Firstly (January) with competitors from men team in Belmeken and after that with women and youth (boys and girls) in Dianabad (March,April and May).

Every boxer completed following psychological tests (questionnaires):

1. Test for Personality Hardiness. Building a tool for measuring personality hardiness began in 1982 and in 1989 resulted (Bartone, Ursano, Wright, Ingraham) a questionnaire with 45 items. The instrument has tree scales- Commitment, Control and Challenge.

2. The Aggression Questionnaire (Buss, \& Perry, 1992). The questionnaire contains 29 items and four scales- Physical aggression, Verbal aggression, Anger and Hosility

3. Big Five Personality Test developed by Goldberg (1992). The scale includes 50 items and five scalesOpenness, Conscientiousness, Agreeableness, Neuroticism and Extraversion.
The topic of research are psychological stability, aggressiveness and personality characteristics of elite boxers in Bulgaria.

The research was done among 30 men and women boxers between 16 and 37 years with different level of practice and qualification from Bulgarian national team. The mean age of researched individuals is 21 . For the purpose of the research the players were divided into groups as follows: according to their according to their age: $16-20$ (18 boxers), over 20 (12 boxers).

The data from the research are processed with statistical software SPSS 23 and variance and comparative analysis. The distribution of the data was determined by the test of Kolmogorov - Smirnov.

\section{RESULTS AND DISCUSSION}

The results of the average values of "Big five" test show that Agreeableness $(M=39,36)$ is the parameter with the highest score - Figure.1. This trait is associated with high level of politeness, trustiness and strong behavior control. The boxers score more in average than the typical results of Bulgarian population. The lowest scale from "Big five" is $(\mathrm{M}=$ 33,36), which scale describe the emotional stability. The questionnaire for personality hardiness shows that the leading scale is Control $(M=30,76)$, which refers to the tendency to believe and act as if one could influence the course of events.

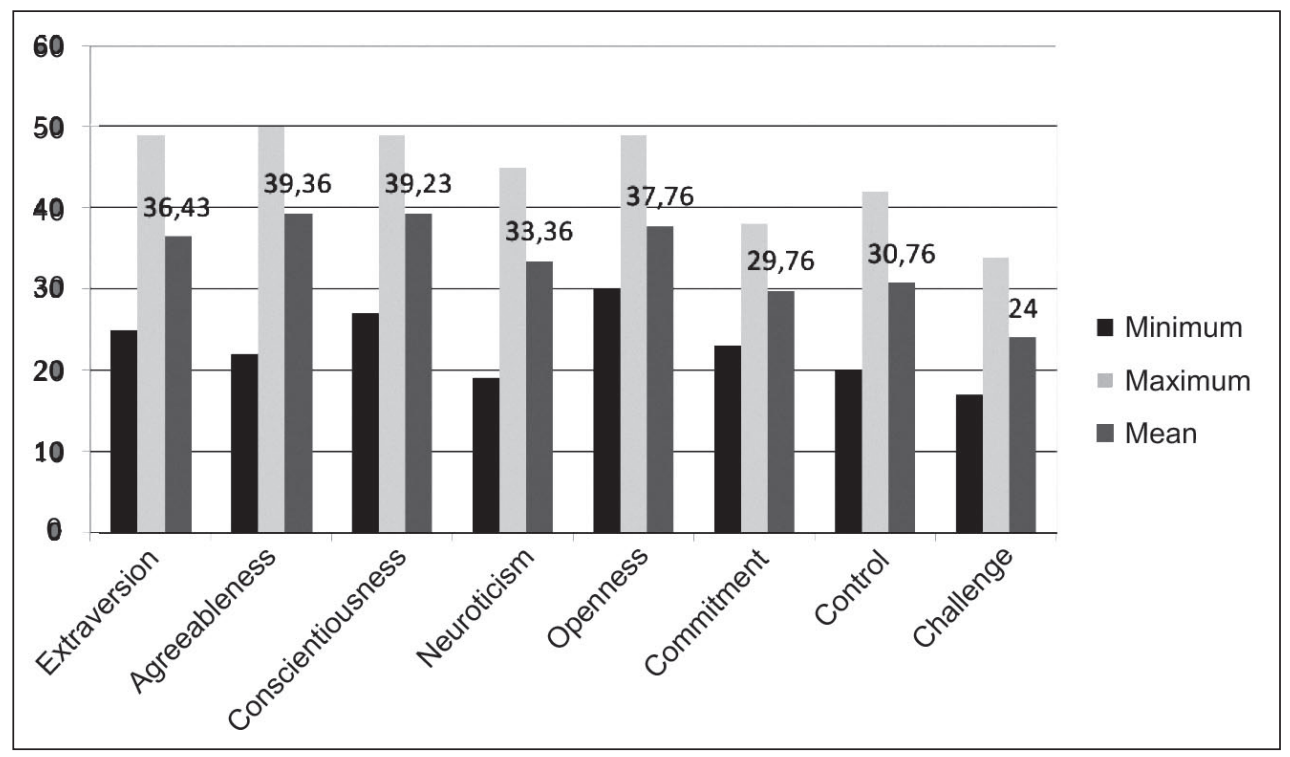

Figure 1. Mean, maximum and minimum values of Extraversion, Agreeableness, Conscientiousness, Neuroticism, Openness from "Big Five" scale and Commitment, Control and Challenge from "Hardiness" scale.

The mean values of "The Aggression Question- naire" scale show that the Verbal aggression is with 
highest score and the lowest parameter it is Hostility. We find out that the results for are very similar to the population, there is no differences - one of the myths is that boxers have high aggressive behavior, but in our research it is not confirmed. The first and second factors represent a motor or instrumental component; anger, which implies psychological activation and preparation for aggression, is the emotional or affective component; and hostility represents the cognitive component. The boxing is aggressive sport, but the successful competitor needs to control their emotions and behavior during practice and competition.

Table 1. Mean, maximum and minimum values of Physical aggression, Verbal aggression, Anger and Hostility from "The Aggression Questionnaire" scale

\begin{tabular}{|l|l|l|l|l|l|}
\hline \multicolumn{1}{|c|}{ Parameter } & \multicolumn{1}{c|}{$\mathbf{N}$} & \multicolumn{1}{c|}{ Minimum } & \multicolumn{1}{c|}{ Maximum } & \multicolumn{1}{c|}{ Mean } & \multicolumn{1}{c|}{ Std. Deviation } \\
\hline Physical aggression & 30 & 1.66 & 4.00 & 2.78 & .648 \\
\hline Verbal aggression & 30 & 1.60 & 5.00 & 3.33 & .720 \\
\hline Anger & 30 & 1.85 & 4.28 & 2.96 & .670 \\
\hline Hostility & 30 & 1.00 & 4.12 & 2.46 & .865 \\
\hline
\end{tabular}

The comparative analysis of the data by gender rience would rather not try new things. They are show statistically significant differences between the parameters. The female boxers are more open to the experience and learning, with more creative thinking and readiness for development - the scale Openness is $\mathrm{T}=3.64 ; \boldsymbol{\alpha}=0.02$. These characteristics describe that women in boxing are open to try and learn in their social activities and sport life. It indicates how open-minded a person is. A person with a high level of openness enjoys trying new things. They are imaginative, curious, and open-minded. Individuals who are low in openness to expeclose-minded, literal and enjoy having a routine. The next scale with statistically significant differences by gender is Challenge scale from the instrument Test for Personality Hardiness. The trait is based on the belief that change, rather than stability, is the normative mode of life. The people like to try a lot of new things, different approaches to act, they have high competitiveness and are ready to overcome the obstacles in every moment. The female boxers have higher level of Challenge, it is important for their career development and personal growth.

Table 2. Comparative analysis of the researched parameters by gender. The table shows only factors with statistically significant differences

\begin{tabular}{|c|c|c|c|c|c|c|}
\hline Parameter & Gender & $\mathbf{N}$ & $\mathbf{M}$ & SD & $\mathbf{t}$ & $\alpha$ \\
\hline \multirow{3}{*}{ Openness } & Men & 18 & 36.16 & 4.42 & \multirow{3}{*}{3.64} & \multirow{3}{*}{0.02} \\
\hline & Women & 12 & 40.16 & 4.66 & & \\
\hline & Total & 30 & 37.76 & & & \\
\hline \multirow{3}{*}{ Challenge } & Men & 18 & 22.66 & 3.54 & \multirow{3}{*}{2.56} & \multirow{3}{*}{0.03} \\
\hline & Women & 12 & 26.00 & 4.67 & & \\
\hline & Total & 30 & 24.00 & & & \\
\hline
\end{tabular}

For the purpose of our survey and in order to as- assume that the behavior to overcome the problems sess the influence between factors we used step regression analysis - Table 3 . The scale Challenge influence significant Verbal aggression $(\beta=, 453, \alpha$ $=, 004)$. The coefficient R2 is 0,653 , which means that we can explain $65 \%$ of the impact variation. The more challenge are competitors, more verbal aggression they have.

The next relationship is Challenge with Physical aggression $(\beta=, 378, \alpha=, 04)$. The parameter influand to achieve the goals is strongly correlated with the level of aggression. We can make a conclusion that sport aggression is one of the important traits for success.

The extraversion affect anger, more open and extravert persons have higher level of anger - $(\beta=$ $, 384, \alpha=, 02)$. This result is related with the expectations of the extraversion personality in the most of the psychological literature. 
Table 3. Results from the Regression analysis.

The table shows only parameters with significant influence

\begin{tabular}{|l|l|l|l|}
\hline \multicolumn{1}{|c|}{ Parameter } & \multicolumn{1}{c|}{$\beta$} & $\alpha$ & \multicolumn{1}{c|}{ R2 } \\
\hline $\begin{array}{l}\text { Challenge } \\
\text { Verbal aggression }\end{array}$ & 0,453 & 0,04 & 0,653 \\
\hline $\begin{array}{l}\text { Challenge } \\
\text { Physical aggression }\end{array}$ & 0,378 & 0,04 & 0,643 \\
\hline $\begin{array}{l}\text { Extraversion } \\
\text { Anger }\end{array}$ & 0,384 & 0,02 & 0,643 \\
\hline
\end{tabular}

\section{DISCUSSION:}

$\checkmark$ The obtained results show that Agreeableness is the parameter with the highest score and is leading in elite boxers in Bulgaria;

$\checkmark$ The female boxers have the higher level of Openness and Challenge, which means more originality, creativity and motivation to achieve future goals;

$\checkmark$ Verbal aggression is higher than physical. There is a lot of aggression in boxing but with clear rules and parameters. The good boxer needs to control his(her) behavior.

$\checkmark$ The more challenge are competitors, more aggression they have. But the important aggressiveness in boxing for the purpose of the victory with fair play.

$\checkmark$ This article is a basic level for future studies in field of Bulgarian boxers in different ages, gender and professional experience.

\section{REFERENCES:}

Andrews, R. (1974). A Spearman rank order correlation for $18 \mathrm{NHL}$ teams. In National Hockey League Guide. Montreal: NHL publishers.

Bartone, P.T (2006). Resilience under military operational stress: Can leaders infl uence hardiness? Military Psychology, 18 (Suppl. 1), S131- S148

Buss, A.H., \& Perry, M. (1992). The aggression questionnaire. Journal of Personality and Social Psychology, 63, 452-459.

Crawford, B. J., Stuart, M. J., Smith, A. M., y Brennan, R. D. (2004). Intimidation in ice hockey: An exploratory assessment. In D. J. Pearsall, \& A. B. Ashare (Eds.), Safety in ice hockey: Fourth volume, (pp. 26-39). West Conshohocken, PA: American Society for Testing and Materials Iancheva, T., (2004). Lichnost I sastezatelna realizaciq, S., NSA PRES. (In Bulgarian) Янчева, T., (2004). Личност и състезателна реализация, С., НСА ПРЕС.

Golby, J., \& Sheard, M. (2004). Mental toughness and hardiness at different levels of rugby league. Personality and Individual Differences, 37, 933-942.

Goldberg, L. R. (1990). An alternative "description of personality": The Big-five factor structure. Journal of Personality and Social Psychology, 59 (6): 1216-1229.

Goldberg, L. R. (1992). The development of markers for the Big-five factor structure. Psychological Assessment, 4, 26-42.

Hull, J.G., Van Treuren, R.R., \& Virnelli, S. (1987). Hardiness and health: A critique and alternative approach. Journal of Personality and Social Psychology, 53, 518-530.

Husman, B.F., \& Silva, J.M. (1984). Aggression in sport: definitional and theoretical considerations, In J.M.Silva, R.S. Weinberg (Eds.), Psychological foundations of sports. Champagin: Human Knictics.

Kobasa, S.C. (1979). Stressful life events, personality, and health: An inquiry into hardiness. Journal of Personality and Social Psychology, 37, 1-11.

Kobasa, S.C. (1982). Commitment and coping in stress resistance among lawyers. Journal of Personality and Social Psychology, 42, 707-717.

Maddi, S.R. (2006). Hardiness: The courage to be resilient. In J.C. Thomas \& D.L. Segal (Eds.), Comprehensive handbook of personality and psychopathology (Vol. 1, pp. 396-321). Hoboken, NJ: Wiley.

Maddi, S.R. \& Kobasa, S.C. (1981). Intrinsic motivation and health. In H.I. Day (Ed.), Advances in intrinsic motivation and aesthetics (pp. 120- 133). New York: Plenum. Mohammadifar, Mohammad Ali and et al. (2010). The comparison of hardiness athlete and non-athlete girl students. Quaterly Journal of Modern Indutrial/ Organizational psychology. Vol (1), No(1): 23-30.

Sinclair, R.R. \& Tetrick, L.E. (2000). Implications of item wording for hardiness structure, relation with neuroticism, and stress buffering. Journal of Research in Personality, 34, 1-25.

Thirer. J. (1993). Aggression. In: R.N. Singer, M. Murphey, L.K. Tennant (Eds.), Handbook of research on sport psychology, pp. 421-435. New York: 
Macmillan.

Williams, J. M., \& Krane, V. (2001). Psychological characteristics of peak performance. In J. M. Williams (Ed.), Applied sport psychology: Personal growth to peak performance (4th ed., pp.

162-178). Mountain View, CA: Mayfield.

Widmeyer, W. N. y Birch, J. S. (1984). Aggression in professional ice hockey: A strategy for success or reaction to failure? Journal of Psychology, 117, 77- 84.

Corresponding author:

Ivan Ivanov, $\mathrm{PhD}$

National Sports Academy „Vasil Levski“Department „Psychology, pedagogy and sociology”

21, Acad. Stefan Mladenov str.

E-mail: ywan13@abv.bg 